\title{
HUBUNGAN PELAYANAN SIRKULASI DENGAN PEMBENTUKAN CITRA PERPUSTAKAAN
} (Studi Deskripsi di Perpustakaan Universitas Pendidikan Indonesia)

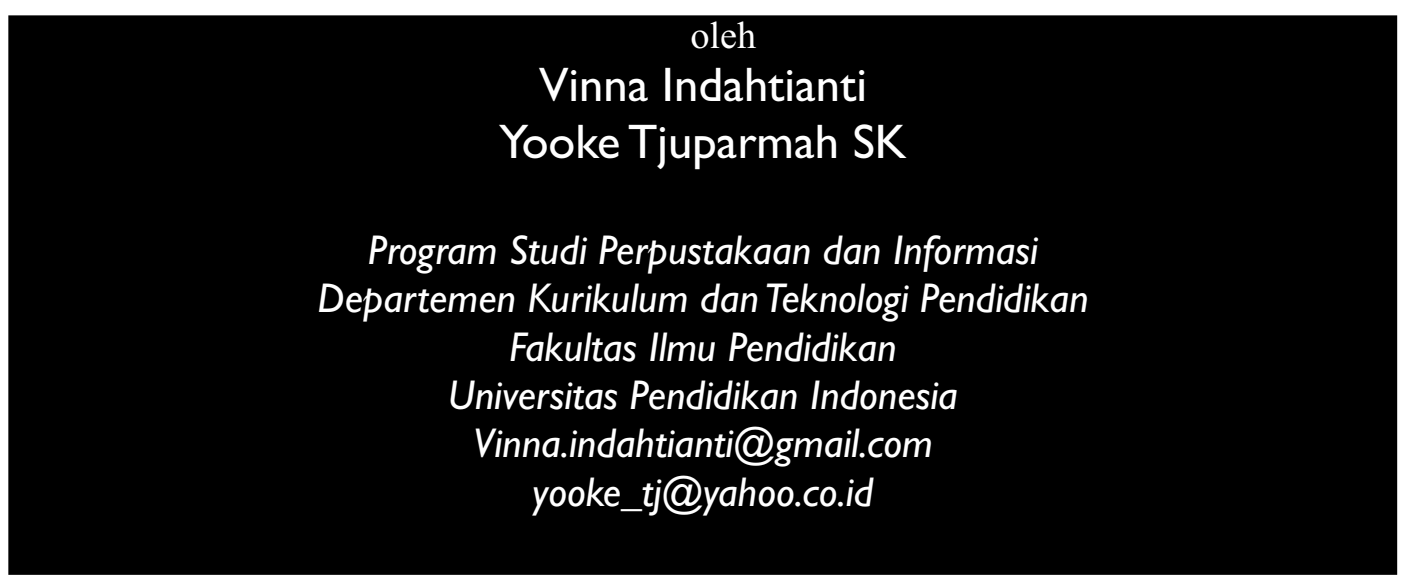

\begin{abstract}
ABSTRAK
Penelitian ini bertujuan untuk mengetahui hubungan pelayanan sirkulasi dengan pembentukan citra Perpustakaan UPI. Adapun secara khusus tujuan penelitian tersebut adalah 1) Untuk mengetahui hubungan fasilitas fisik layanan sirkulasi dengan pembentukan citra Perpustakaan UPI. 2) Untuk mengetahui hubungan kecepatan pelayanan sirkulasi dengan pembentukan citra Perpustakaan UPI. 3) Untuk mengetahui hubungan kemudahan mendapatkan informasi dengan pembentukan citra Perpustakaan UPI. 4) Untuk mengetahui hubungan perhatian pustakawan sirkulasi dengan pembentukan citra Perpustakaan UPI. Penelitian ini menggunakan metode kuantitatif studi deskriptif analisis korelasional yaitu meneliti sejauh mana hubungan pelayanan sirkulasi dengan pembentukan citra Perpustakaan UPI. Populasi dalam penelitian ini adalah jumlah pemustaka Perpustakaan UPI pada bulan Maret 2013. Teknik penarikan sampel menggunakan Accidental Sampling. Analisis data yang digunakan dalam penelitian ini adalah analisis statistik deskriptif, analisis statistik parametris, dan uji hipotesis melalui rumus Koefisien Korelasi oleh Pearson Product Moment. Berdasarkan hasil analisis data diketahui pelayanan sirkulasi memiliki hubungan yang rendah dengan pembentukan citra perpustakaan. Hasil pengujian hubungan pelayanan sirkulasi dengan pembentukan citra perpustakaan menunjukkan indikator fasilitas fisik, kemudahan mendapatkan informasi dan perhatian pustakawan sirkulasi berada pada kategori sedang, sementara indikator kecepatan pelayanan sirkulasi berada pada kategori rendah. Dari hasil penelitian ini, dapat disimpulkan bahwa terdapat hubungan yang positif dan signifikan dari pelayanan sirkulasi dengan pembentukan citra Perpustakaan UPI.
\end{abstract}

Kata Kunci : Pelayanan, Layanan Sirkulasi, Citra Perpustakaan. 


\begin{abstract}
This study aims to determine the correlation between circulation service and image formed of the Indonesian University of Education (UPI) Library. The specific aims of this study are 1) to determine the correlation between the physical facilities and the image formed, 2) to determine the correlation between the speed of service and the image formed, 3) to determine the correlation between of the easiness of getting information and the image formed. 4) to determine the correlation between the attention of librarian and the image formed. This study uses quantitative method with the correlational analysis that investigate the correlation between circulation service and image formed of the library. The population of this study is the number of visitors of Indonesian University of Education Library in March 2013. Accidental sampling is used in this study. The data of this study is analyzed by descriptive statistical analysis, parametric statistical analysis, and hypothesis testing through the coefficients formula by Pearson Product Moment Correlation. Acording to the result of data analysis, there is low corelation between circulation service and image formed of the library. The result of corelation test between circulation service and image formed show that the physical facilities indicator, the easiness of getting information, and the librarian attention is in the medium category. Meanwhile, the speed of service indicator is in low category. From the result of the study, it can be concluded that there is a positive and significant correlation between the circulation services and image formed of UPI Library.
\end{abstract}

Keywords : Service, Circulation Service, Library Image 


\section{PENDAHULUAN}

Pada hakikatnya, perpustakaan perguruan tinggi merupakan sarana penunjang yang sangat penting pada setiap program pendidikan dan pengajaran, penelitian, maupun pengabdian masyarakat. Untuk mencapai sasarannya, pustakawan berperan penting dalam meningkatkan kualitas layanan perpustakaan. Fatmawati (2012: 1) berpendapat bahwa "...kualitas dipandang sebagai salah satu alat untuk mencapai keunggulan kompetitif (competetitive advantage)." Perpustakaan memiliki fungsi diantaranya; fungsi edukasi, sumber informasi, penunjang riset, rekreasi, publikasi, deposit dan interpretasi informasi. Maka dari itu, tugas dari perpustakaan perguruan tinggi adalah mengembangkan koleksi, mengolah dan merawat bahan pustaka, memberi layanan serta melaksanakan administrasi perpustakaan. Sesuai dengan tugas perpustakaan perguruan tinggi untuk memberikan layanan yang dapat memuaskan pemustaka, dibutuhkan SDM yang berkualitas dan memiliki kompetensi yang bisa menghasilkan prestasi dan kinerja yang baik.

Perpustakaan UPI merupakan perpustakaan perguruan tinggi yang memiliki tujuan utama memberikan layanan kepada pemustaka di lingkungan sivitas akademika. Salah satu jenis layanan yang terdapat di perpustakaan UPI adalah layanan sirkulasi. Dalam ilmu perpustakaan, sirkulasi sering dikenal sebagai kegiatan peminjaman buku dan materi lainnya. Akan tetapi pelayanan sirkulasi sering dianggap sebagai kegiatan yang menyeluruh dalam proses pemenuhan kebutuhan informasi pemustaka yang beragam, karena selain sering dimanfaatkan pemustaka mulai dari peminjaman, pengembalian, menggunakan fasilitas yang ada di bagian sirkulasi, posisi layanan sirkulasi di perpustakaan UPI berada di depan dan menjadi pusat perhatian pemustaka yang sekaligus tempat bagi setiap pertanyaan. Dalam hal ini, pustakawan sirkulasi harus memiliki keterampilan berkomunikasi yang dapat dipahami oleh para pemustaka dalam rangka meningkatkan citra perpustakaan UPI yang modern dan dinamis. Citra dapat terbangun dari persepsi dan penilaian pemustaka terhadap pelayanan sirkulasi diukur dari segi fasilitas fisik, kecepatan pelayanan, kemudahan mendapakan informasi dan perhatian pustakawan sirkulasi yang akan berdampak pada citra perpustakaan.

Berdasarkan pengamatan yang penulis lakukan sebelum melaksanakan penelitian, penulis mendapatkan fakta mengenai pemustaka yang kurang mendapatkan respon dari pustakawan sirkulasi. Pernyataan tersebut menjadi hal yang sering terdengar apabila pemustaka menyebarkan informasi yang dilihat kepada teman atau masyarakat sekitar. Padahal citra perpustakaan sangat esensial, karena yang dapat membangun citra adalah dari yang dirasakan melalui bagaimana pustakawan menghadapi pemustaka. fakta lain yang penulis temukan alat sirkulasi yakni MPS (alat pinjam mandiri) sering mengalami gangguan.

Identifikasi permasalahan dari penelitian ini antara lain pelayanan yang diberikan pustakawan sirkulasi kurang memuaskan pemustaka karena respon pustakawan yang kurang baik dalam menanggapi pertanyaan dari pemustaka, pemilihan mebeler di layanan sirkulasi pada perpustakaan UPI dinilai kurang sesuai dengan kenyamanan pemustaka dan MPS (alat pinjam mandiri) terkadang mengalami gangguan sehingga pemustaka menjadi terhambat dalam melakukan peminjaman dan pengembalian buku. Rumusan masalah dalam penelitian ini dibagi menjadi dua 
yaitu rumusan masalah umum dan rumusan masalah khusus. Rumusan masalah umum yaitu bagaimana hubungan pelayanan sirkulasi dengan pembentukan citra perpustakaan UPI. Rumusan masalah khusus yaitu bagaimana fasilitas fisik layanan sirkulasi dengan pembentukan citra pada perpustakaan UPI, Bagaimana kecepatan pelayanan sirkulasi dengan pembentukan citra pada perpustakaan UPI, bagaimana kemudahan mendapatkan informasi pada pelayanan sirkulasi dengan pembentukan citra perpustakaan UPI, bagaimana perhatian pustakawan sirkulasi dengan pembentukan citra perpustakaan UPI.

Dalam penelitian ini terdapat tujuan penelitian umum dan tujuan penelitian khusus. Tujuan penelitian umum adalah untuk mengetahui dan memperoleh informasi mengenai hubungan pelayanan sirkulasi dengan pembentukan citra perpustakaan. Sedangkan tujuan penelitian khusus antara lain untuk mengetahui fasilitas fisik layanan sirkulasi dengan pembentukan citra pada perpustakaan UPI, untuk mengetahui kecepatan pelayanan sirkulasi dengan pembentukan citra pada perpustakaan UPI, untuk mengetahui kemudahan mendapatkan informasi pada pelayanan sirkulasi dengan pembentukan citra perpustakaan UPI, untuk mengetahui perhatian pustakawan sirkulasi dengan pembentukan citra perpustakaan UPI. Manfaat dari hasil penelitian ini diharapkan dapat memberikan informasi dan bahan masukan dalam rangka peningkatan pelayanan sirkulasi perpustakaan UPI, dapat meningkatkan pemahaman pemustaka secara mendalam mengenai ragam layanan yang ada pada layanan sirkulasi, dan untuk peneliti selanjutnya dapat memberikan gambaran pelayanan sirkulasi perpustakaan UPI.

\section{PEMBAHASAN}

Pelayanan perpustakaan sebagai usaha untuk membantu menyiapkan atau mengurus apa yang diperlukan pemustaka untuk memenuhi kebutuhan informasi yang dapat memuaskan pemustaka. Dari pelayanan sirkulasi akan menghasilkan persepsi pemustaka terkait dengan kualitas pelayanan yang dirasakan oleh pemustaka sehingga akan terbentuk pencitraan perpustakaan. Pelayanan sirkulasi berperan penting dalam suatu perpustakaan. Menurut Zeithaml, Parasuraman and Berry dalam (Arief, 2006: 130) “...terdapat kriteria pelayanan untuk menilai kualitas pelayanan jasa yaitu fasilitas fisik, kecepatan dalam pelayanan, kemudahan mendapatkan pelayanan, dan perhatian kepada pelanggan." Dalam hal layanan sirkulasi, fasilitas merupakan bukti fisik yang ada di layanan sirkulasi seperti meja layanan, tata pencahayaan, furniture dari meja layanan yang sesuai dengan warna perpustakaan karena menurut Craig-Less dalam (Tjiptono, 2007: 96) mengemukakan bahwa “... warna mempengaruhi perasaan dan tidakan setiap orang." Kecepatan dalam memberikan pelayanan dimaksudkan suatu kemauan atau kesediaan pustakawan sirkulasi ntuk membantu dan memberikan layanan dengan tanggap dan cepat (responsif) kepada pemustaka. Selain itu, pustakawan harus beranggapan pemustaka sebagai raja yang sangat menetukan dan berkembangnya sebuah perpustakaan dalam rangka meningkatkan citra sekaligus citra perpustakaan. Sesuai dengan pendapat Boyce dalam (Achmad, 2012: 36) mengemukakan bahwa "...pelanggan layaknya seorang raja, ini berarti pelanggan sebagai pusat organisasi, sehingga pelanggan menggerakkan apa yang dikerjakan oleh sebuah usaha" Kemudahan mendapatkan informasi 
(akses), artinya tempat dan lokasi serta sarana pelayanan yang memadai, mudah dijangkau oleh pemustaka dan dapat memanfaatkan teknologi informasi seperti MPS. Selain itu, peranan pustakawan sirkulasi sangat penting dalam memenuhi kebutuhan informasi dengan cara pustakawan sirkulasi harus menyampaikan informasi kepada pemustaka dengan bahasa yang mudah dipahami dan mengerti akan informasi yang diinginkan, seperti yang dikemukakan oleh Achmad (2012: 89) bahwa "...perusahaan harus menyesuaikan dengan bahasa pelanggan yang bermacam-macam, baik berbicara dengan pelanggan yang berpendidikan tinggi maupun pelanggan yang biasabiasa saja. Yang termasuk didalamnya adalah memberi penjelasan mengenai jasa yang ditawarkan dan meyakinkan pelanggan bahwa masalahnya akan segera ditangani." Perhatian pustakawan sirkulasi berarti pustakawan sirkulasi memberikan perhatian yang bersifat individual atau pribadi kepada pemustaka dan berupaya untuk memenuhi keinginan atau kebutuhannya yang meliputi kemudahan dalam melakukan hubungan komunikasi yang baik. Apabila aspek kriteria pelayanan yang diberikan oleh pustakawan sirkulasi dapat memuaskan pemustaka, maka persepsi pemustaka terhadap perpustakaan akan berdampak positif, sebaliknya jika aspek tersebut tidak terlaksana dengan baik maka persepsi pemustaka terhadap perpustakaan akan berdampak negatif.

Menurut Bill Canton dalam (Soemirat, 2002: 111) mengatakan bahwa "...citra adalah kesan, perasaan, gambaran diri public terhadap perusahaan; kesan yang dengan disengaja diciptakan dari suatu obyek, orang atau organisasi." Dari meja layanan sirkulasi akan dikembangkan gambaran citra perpustakaan UPI yang modern dan dinamis, sehingga seluruh kegiatan perpustakaan akan diarahkan dan terfokus kepada bagaimana memberikan layanan yang tidak hanya dilihat hasilnya saja melainkan memperhatikan proses pemberian jasa layanan yang baik sebagaimana dikehendaki oleh pemustaka. Adapun kriteria pustakawan dalam memberikan pelayanan menurut Tjuparmah (2008: 54) bahwa "...para pelaksana yang mengimplementasikan strategi membuat agenda tindakan strategi untuk menjawab berbagai pertanyaan: 1) apa yang harus diketahui, 2) apa yang akan dilakukan, 3) berapa waktu dan perhatian yang diperlukan untuk mengimplementasikan perencanaan tersebut." Dengan demikian pustakawan harus memiliki pemahaman secara menyeluruh mengenai informasi yang ada di perpustakaan informasi tersebut dapat tersampaikan kepada pemustaka melalui pelayanan yang dapat memuaskan pemustaka. Kepuasan pemustaka berkaitan erat dengan koleksi perpustakaan, fasilitas yang memadai, jenis jasa peprustakaan yang diberikan serta bagaimana pustakawan memberikan jasa kepada pemustakanya.

Perpustakaan yang mampu memberikan layanan prima mempunyai citra yang baik. Citra yang memberikan nilai lebih kepada perpustakaan sebagai institusi. Perpustakaan akan menjadi popular. Perpustakaan akan menjadi rujukan untuk perpustakaan lain dalam memberikan layanan prima. Perpustakaan akan lebih banyak menerima kunjungan karena citranya semakin baik. Citra yang baik akan mendorong nama baik lembaga dimana perpustakaan itu berada. Menurut Sutojo (2010: 55) Tahapan untuk mempopulerkan citra perusahaan terdiri dari tiga kegiatan berurutan, yaitu "...pembentukan persepsi, pemeliharaan persepsi, dan perubahan persepsi." Pembentukan persepsi merupakan langkah pertama dalam upaya 
membentuk citra tentang jati diri perpustakaan, Citra yang dibentuk harus mencerminkan diri perpustakaan berdasarkan kenyataan. Di lain pihak, walaupun citra yang diketengahkan harus nyata, perpustakaan tidak diharuskan mengetengahkan kekurangan mereka. Perpustakaan perlu menguasai aliran informasi tentang diri mereka ke pemustaka. Menurut Sutojo (2010: 55), agar dapat menguasai aliran informasi tersebut mereka perlu melakukan hal-hal sebagai berikut: menentukan tipe citra yang akan dipopulerkan; mengambil inisiatif mempopulerkan citra tersebut dikalangan segmen sasaran; tidak mengetengahkan citra secara berlebihan; membentuk citra secara bertahap; dan; memilih sarana penyimpanan citra yang baik. Citra yang berhasil dibentuk wajib dipertahankan dan dipelihara dengan baik, Hal ini diperlukan karena keadaan perpustakaan tidak pernah permanen yang selalu mengalami berbagai macam perubahan. Apabila tidak dipertahankan dengan baik, citra perpustakaan dapat menurun, bahkan dilupakan. Maka dari itu, perpustakaan harus mempertahankan citra dengan memberikan pelayanan yang dapat memuaskan pemustaka dan melaksanaan program periklanan citra dan hubungan masyarakat sesuai dengan rencana usaha jangka menengah yang telah disusun. Citra pemustaka terhadap perpustakaan yang merugikan wajib dirubah. Apabila perpustakaan mengetahui tipe citra yang dipopulerkan di masyarakat tidak tepat, maka pustakawan wajib meneliti sebab terjadinya penyimpangan tersebut. Penyimpangan citra dapat dilakukan dengan menyelenggarakan riset perilaku pemustaka yang memanfaatkan ragam layanan yang ada di perpustakan.

Menurut Dwiajie (2011: 8) “...perpustakaan UPI ingin menampilkan dan mencerminkan gambaran citra perpustakaan yang modern dan dinamis." Perpustakaan yang modern dimaksudkan sebagai gambaran eksistensi perpustakaan UPI selalu mengadaptasi perkembangan teknologi informasi dan komunikasi yang ada sebagai upaya peningkatan kinerja Perpustakaan. Sedangkan perpustakaan yang dinamis, berarti perpustakaan UPI selalu melakukan inovasi-inovasi baru dalam layanan yang diberikan kepada pemustaka guna memenuhi kebutuhan informasi pemustaka yang semakin kompleks seiring perkembangan teknologi informasi dan komunikasi. Citra perpustakaan yang modern dan dinamis dapat terbangun dari yang tampak, terdengar dan dirasakan serta pandangan pertama pada pelayanan sirkulasi yang akan berdampak penilaian pemustaka terhadap citra perpustakaan. Penilaian tersebut dapat berperingkat baik, sedang atau buruk yang dapat mempengaruhi keberhasilan kegiatan pelayanan. Citra buruk melahirkan dampak negatif pada perpustakaan, tetapi jika perpustakaan dikelola secara professional, maka perpustakaan tersebut akan berusaha keras merubah persepsi pemustaka yang tidak menguntungkan dengan cara memperbaiki dan menganalisis yang menyebabkan terjadinya perubahan persepsi pemustaka. Penyebab tersebut mungkin ada pada kepribadian atau kinerja pustakawan dan kebijaksanaan perpustakaan bahkan cara perpustakaan mengiklankan citra kurang maksimal. Agar program mempopulerkan citra berhasil seperti yang diharapkan, manajemen perpustakaan wajib mengetengahkan kelebihannya secara ringkas, berciri khas, berkesinambungan, dan realistis. Sehingga dalam jangka panjang citra yang baik membawa banyak manfaat menghadapi berbagai macam krisis.

Populasi dalam penelitian ini adalah 
panjang citra yang baik membawa banyak manfaat yang dapat dinikmati pada saat mengalami masa jaya maupun pada saat mereka menghadapi berbagai macam krisis.

Populasi dalam penelitian ini adalah jumlah pemustaka Perpustakaan UPI pada bulan Maret 2013 adalah sebanyak 36.000 orang. Teknik penarikan sampel menggunakan accidental Sampling. Banyaknya sampel dalam penelitian ini adalah 100 orang pemustaka. metode yang digunakan dalam penelitian ini adalah metode deskriptif dengan menggunakan pendekatan kuantitatif, yakni mendeskripsikan mengenai hubungan pelayanan sirkulasi dengan pembentukan citra perpustakaan UPI. Analisis data yang digunakan dalam penelitian ini adalah analisis statistik deskriptif, analisis statistik parametris, dan uji hipotesis melalui rumus Koefisien Korelasi oleh Pearson Product Moment. Hasil uji korelasi pada tabel di bawah ini menunjukkan nilai korelasi antara pelayanan sirkulasi dengan pembentukan citra perpustakaan berkorelasi sebesar 0,308 dengan $\mathrm{n} 100$, taraf kesalahan 0,05 dan $r$ tabel 0,196.

Tabel 1.1

Koefisien Korelasi antara X dengan Y

\begin{tabular}{|c|c|c|}
\hline & $\mathrm{X}$ & $\mathrm{Y}$ \\
\hline $\begin{array}{l}\text { X Pearson Correlation } \\
\text { Sig. (2-tailed) } \\
\text { N }\end{array}$ & 100 & $\begin{array}{r}.308^{* *} \\
.002 \\
100 \\
\end{array}$ \\
\hline $\begin{array}{l}\text { Y Pearson Correlation } \\
\text { Sig. (2-tailed) } \\
\text { N }\end{array}$ & $\begin{array}{r}.308^{* *} \\
.002 \\
100\end{array}$ & 100 \\
\hline
\end{tabular}

Berdasarkan tabel di atas, diperoleh nilai koefisien korelasi sebesar 0,308 dan karena $\mathrm{n}>30$ maka untuk menentukan signifikansi dengan menggunakan uji $t$ (Sugiyono, 2003:234) dengan syarat:
1. Jika $\mathrm{t}_{\text {hitung }}<\mathrm{t}_{\text {tabel }}$, maka $\mathrm{H}_{0}$ diterima dan $\mathrm{H}_{1}$ ditolak;

2. Jika $\mathrm{t}_{\text {hitung }}>\mathrm{t}_{\text {tabel }}$, maka $\mathrm{H}_{0}$ ditolak dan $\mathrm{H}_{1}$ diterima.

Karena nilai $r$ telah diketahui yakni 0,308 maka untuk mengetahui apakah nilai $r$ tersebut memiliki arti atau tidak, maka dilakukan uji hipotesis korelasi Pearson dengan rumus yakni sebagai beriknt.

$$
\begin{aligned}
t=\frac{r \sqrt{n-2}}{\sqrt{1-r^{2}}} & =\frac{0,308 \sqrt{100-2}}{\sqrt{(1-0,095)}} \\
& =\frac{3,049}{0,951}=3,206
\end{aligned}
$$

Dari perhitungan nilai $r$ dan $\mathrm{t}$ diatas maka, peneliti menyimpulkannya sebagai berikut:

Tabel 1.2

Kesimpulan uji korelasi

\begin{tabular}{|c|c|c|c|c|}
\hline $\mathrm{R}$ & $\begin{array}{c}\text { Kriteri } \\
\mathrm{a}\end{array}$ & $\mathrm{t}_{\text {hitung }}$ & $\mathrm{t}_{\text {tabel }}$ & $\begin{array}{c}\text { Keteranga } \\
\mathrm{n}\end{array}$ \\
\hline $\begin{array}{c}0,30 \\
8\end{array}$ & $\begin{array}{c}\text { Renda } \\
\mathrm{h}\end{array}$ & $\begin{array}{c}3,20 \\
6\end{array}$ & $\begin{array}{c}1,98 \\
4\end{array}$ & Signifikan \\
\hline
\end{tabular}

Dari hasil perhitungan diperoleh nilai $\mathrm{t}_{\text {hitung }}=3,206$ dan $\mathrm{t}_{\text {tabel }}=1,984$, maka $\mathrm{t}_{\text {hitung }}>$ $\mathrm{t}_{\text {tabel }}$ artinya hipotesis umum diterima dengan signifikansi 3,206 > 1,984, kriterianya signifikan. Maka dapat disimpulkan bahwa terdapat hubungan yang signifikan antara pelayanan sirkulasi dengan pembentukan citra perpustakaan. Hubungan ini ditunjukkan dengan nilai korelasi sebesar 0,308 yang termasuk kedalam kriteria rendah. Untuk mendapatkan hasil yang lebih akurat peneliti juga melakukan uji korelasi terhadap setiap indikator variabel $\mathrm{X}$ terhadap Y, uji ini dilakukan untuk mengetahui indikator mana yang memiliki hubungan paling besar dengan variabel Y. Hasil perhitungan korelasi dipaparkan pada tabel dibawah ini. 
Tabel 1.3

Koefisien Korelasi Indikator X Terhadap Y

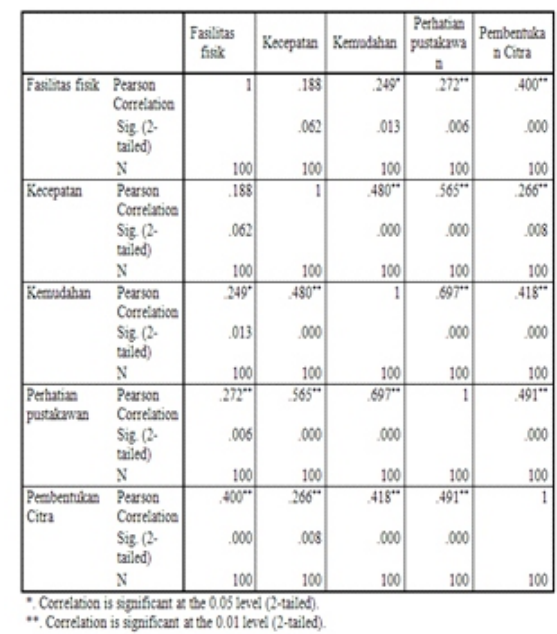

Korelasi antara indikator X terhadap Variabel Y yakni indikator pertama (fasilitas fisik) berkorelasi sebesar 0,400, indikator kedua (kecepatan pelayanan) berkorelasi sebesar 0,266, indikator ketiga (kemudahan mendapatkan informasi) berkorelasi sebesar 0,418 dan indikator keempat (perhatian pustakawan) berkorelasi sebesar 0,491. Dengan demikian indikator fasilitas fisik termasuk kategori pada tingkat hubungan sedang, indikator kecepatan pelayanan termasuk kategori pada tingkat hubungan rendah, sementara indikator kemudahan mendapatkan informasi dan indikator perhatian pustakawan berada pada tingkat hubungan sedang.

\section{SIMPULAN}

Dari hasil penelitian yang telah dilakukan, dapat ditarik kesimpulan sebagai berikut: kesimpulan umum dari penelitian ini adalah terdapat hubungan yang positif dan signifikan antara pelayanan sirkulasi dengan pembentukan citra. Pelayanan sirkulasi memiliki hubungan yang rendah dengan pembentukan citra perpustakaan.

Berdasarkan hasil penelitian yang telah dilakukan untuk mengetahui hubungan pelayanan sirkulasi yang meliputi fasilitas fisik layanan sirkulasi, kecepatan pelayanan sirkulasi, kemudahan mendapatkan infromasi, dan perhatian pustakawan sirkulasi dengan pembentukan citra perpustakaan UPI, maka dapat diambil kesimpulan khusus pada penilitian ini yaitu, terdapat hubungan yang signifikan antara fasilitas fisik layanan sirkulasi dengan pembentukan citra perpustakaan. Berdasarkan kategori dalam interpretasi terhadap koefisien korelasi menunjukkan bahwa fasilitas fisik layanan sirkulasi memiliki hubungan yang sedang dengan pembentukan citra perpustakaan.

Terdapat hubungan yang signifikan antara kecepatan pelayanan sirkulasi dengan pembentukan citra perpustakaan. Berdasarkan kategori dalam interpretasi terhadap koefisien korelasi menunjukkan bahwa kecepatan pelayanan sirkulasi memiliki hubungan yang rendah dengan pembentukan citra perpustakaan.

Terdapat hubungan yang signifikan antara kemudahan mendapatkan informasi dengan pembentukan citra perpustakaan. Berdasarkan kategori dalam interpretasi terhadap koefisien korelasi menunjukkan bahwa kemudahan mendapatkan informasi memiliki hubungan yang sedang dengan pembentukan citra perpustakaan.

Terdapat hubungan yang signifikan antara perhatian pustakawan sirkulasi dengan pembentukan citra perpustakaan. Berdasarkan kategori dalam interpretasi terhadap koefisien korelasi menunjukkan bahwa perhatian pustakawan sirkulasi memiliki hubungan yang sedang dengan pembentukan citra perpustakaan.

\section{DAFTAR PUSTAKA}

Achmad. (2012). Layanan Cinta: perwujudan layanan prima $^{++}$ perpustakaan. Jakarta: Sagung Seto. 
Arief, Muhtosim. (2006). Pemasaran Jasa \& Kualitas Pelayanan: bagaimana mengelola kualitas pelayanan agar memuaskan pelanggan. Malang: Bayumedia.

Arikunto, S. (2010). Prosedur

Penelitian:Pendekatan Praktik. Jakarta: Rineka Cipta.

Dalyono, M. (2009). Psikologi

Pendidikan. Jakarta: Rineka Cipta.

Departemen Pendidikan Nasional. (2008). Kamus Besar Bahasa Indonesia Pusat. Jakarta: PT Gramedia Pustaka Utama.

DIKTI. (TT). Perpustakaan Perguruan Tinggi: buku pedoman. Jakarta: DIKTI. Jefkins, F. (2004). Public Relations. Jakarta: Erlangga.

Kirom, B. (2010). Mengukur Kinerja Pelayanan dan Kepuasan Konsumen. Bandung: Pustaka Reka Cipta.

Lasa HS. (1994). Jenis-jenis Pelayanan Informasi Perpustakaa: sirkulasi, referensi. Yogyakarta: Gadjah Mada University Press.

Nasution, M. N. (2004). Manajemen Jasa Terpadu: Total Service Managemen. Bojong Kerta: Ghalia Indonesia.

Nasution, S. (1984). Metode Research.

Bandung: Bumi Aksara.

Nawawi, H. (2001). Metode Penelitian Bidang Sosial. Yogyakarta: Gadjah Mada University Press.

Rahmayanty, N. (2012). Manajemen Pelayanan Prima. Yogyakarta: Graha Ilmu.

Rakhmat, J. (2009). Metode Penelitian Komunikasi. Bandung: Remaja Rosdakarya.

Siswanto, S. (2004). Membangun Citra Perusahaan. Jakarta: Damar Mulia Pustaka.

Soeatminah. (1992). Perpustakaan, Kepustakawanan dan Pustakawan. Yogyakarta: Kanisius.
Soemirat, S. (2010). Dasar-dasar Public Relations. Bandung: Remaja Rosdakarya.

Sugiyono. (2012). Metode Penelitian Kuantitatif, Kualitatif, dan $R \& D$. Bandung: Alfabeta.

Sulistyo-Basuki. (1994). Pengantar Ilmu Perpustakaan. Jakarta: PT Gramedia Pustaka Utama.

Sutarno, NS. (2006). Perpustakaan dan Masyarakat. Jakarta: Sagung Seto. Sutopo. (2000). Pelayanan Prima. Jakarta: Lembaga Admistrasi Negara. Tjipton, F. (2007). Service, Quality \& Satisfaction. Yogyakarta: Andi Offset.

Trimo, S. (1992). Pedoman Pelaksanaan Peprustakaan. Bandung: Remaja Rosdakarya.

Umar, H. (1998). Riset Sumber Daya Manusia. Jakarta: Gramedia Pustaka.

Universitas Pendidikan Indonesia. (2011). Pedoman Penulisan Karya Ilmiah. Bandung: UPI.

Wasesa, S. A. (2006). Strategi Public Relations. Jakarta: Gramedia Pustaka Utama.

Yusup, P. M \& Priyo, S. (2010). Teori dan Praktik Penelusuran Informasi:Information Retrieval. Jakarta: Kencana. . (2007). Undang-Undang Republik Indonesia Nomor 43 Tahun 2007 tentang Perpustakaan.

\section{JURNAL}

Fatmawati, E. (2012). Evaluasi Kualitas Layanan Perpustakaan FEB UNDIP berdasarkan Harapan dan Persepsi Pemustaka dengan Metode LibQUAL. Berkala ilmu perpustakaan dan informasi, VIII (1), pp.1-32,

Nurdiyani, Y. (2011). Pelayanan UPT Perpustakaan Unkhair Minat Mahasiswa Dalam 
Memanfaatkan UPT

Perpustakaan Universitas

Kahirun Tenate. Berkala ilmu

perpustakaan dan informasi, VII

(2), pp.35-43.

SKRIPSI

Kesaulya, D. (2007). Tanggapan

Pengguna tentang Kemampuan

Pustakawan Dalam Memberikan

Jasa Layanan Sirkulasi di

Perpustakaan UNDAP. Fakultas

Ilmu Komunikasi: UNPAD.

Rosalia, V. (2007). Persepsi Pengguna

terhadap Layanan sirkulasi.

Fakultas Ilmu Komunikasi:

UNPAD.

Sulastri, D. (2008). Persepsi Siswa terhadap Perpustakaan. Fakultas Ilmu Budaya: UI.

\section{TESIS}

Dwiajie, M. (2011). Pengaruh Desain Interior Perpustakaan terhadap Citra Perpustakaan. Magister Ilmu Komunikasi: UNPAD.

\section{DISERTASI}

Yooke, T.S. K . (2010). Manajemen Perpustakaan Perguruan Tinggi: studi kasus upaya peningkatan layanan Perpustakaan UPI dengan digital library.UPI. 